\title{
Synthesis and Metalation of Catechol-Functionalized Porous Organic Polymers
}

\author{
Mitchell H. Weston, Omar K. Farha,* Brad G. Hauser, Joseph T. Hupp,* and SonBinh T. Nguyen* \\ Department of Chemistry and the International Institute for Nanotechnology, Northwestern University, 2145 Sheridan Road, \\ Evanston, Illinois 60208-3113, United States
}

\section{Supporting Information}

ABSTRACT: Robust catechol-functionalized porous organic polymers (POPs) with tunable porosities $\left(560-1050 \mathrm{~m}^{2} / \mathrm{g}\right.$ ) and degrees of functionalization were synthesized using a cobaltcatalyzed acetylene trimerization (CCAT) strategy. Post-synthesis metalation can be readily carried out with a wide range of metal precursors ( $\mathrm{Cu}^{\mathrm{II}}, \mathrm{Mg}^{\mathrm{II}}$, and $\mathrm{Mn}^{\mathrm{II}}$ salts and complexes), resulting in metalated POPs with enhanced heat of hydrogen adsorptions compared to the starting nonmetalated materials.

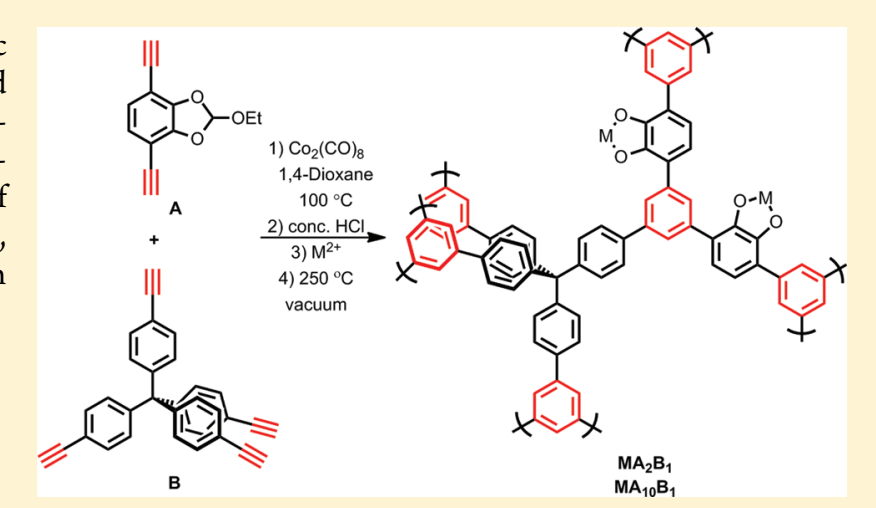

KEYWORDS: porous organic polymers, metal catecholates, hydrogen storage

\section{INTRODUCTION}

Catechols have been used extensively as ligands in coordination chemistry; ${ }^{1}$ however, homogeneous synthetic strategies often result in bis- or tris-chelation motifs that saturate metal coordination sites and preclude their use in binding/ recognition. Our long-time interests in porous metal-containing materials led us to hypothesize that integrating rigid catecholcontaining building blocks into a porous solid would lead to an isolated catechol environment that can bind single metal atoms, resulting in monocatecholated metal complexes with high degrees of coordinative unsaturation. Integrated into a rigid, highly cross-linked, microporous solid organic polymer ${ }^{2-6}$ as "support", such discrete, monocatecholated complexes would be highly useful for applications such as gas storage, ${ }^{7-12}$ catalysis, ${ }^{13-18}$ or gas separations. ${ }^{17,19-21}$ Notably for divalent metal ions, the cationic charges will be offset by the dinegative catecholate, leaving the metal site and the polymer pores free of charge-compensating anions. Such charge-compensating anions, as those accompanying metalated bipy-containing POPs $^{16,18}$ and porphyrin POPs ${ }^{14,15}$ possessing tri- and tetravalent metal centers, can potentially reduce available pore volume and overall porosity.

Herein, we report the synthesis of a series of porous organic polymers (POPs ${ }^{19,22,23}$ ) possessing a high density of isolated catechol units that can be tuned through the modulation of comonomer stoichiometries during copolymerization. Metalation of these catechol-containing POPs proceeds with ease in the presence of a wide range of metal ions. Consistent with the anticipated coordinative unsaturation, several metalated ver- sions of these POPs were found to display enhanced heat of adsorption for hydrogen storage.

\section{EXPERIMENTAL SECTION}

2.1. Synthesis of Polymers. $P O P A_{2} B_{1}$. In a glovebox, an 8 dram screw cap vial was charged with 2,3-(ethoxymethylenedioxy)-1,4-diethynylbenzene (A, $38 \mathrm{mg}, 0.18 \mathrm{mmol}$ ) and tetrakis(4-ethynylphenyl)methane (B, $37 \mathrm{mg}, 0.09 \mathrm{mmol}$ ). This mixture was dissolved in dry, deoxygenated 1,4-dioxane (4 $\mathrm{mL})$ and $\mathrm{Co}_{2}(\mathrm{CO})_{8}(30 \mathrm{mg}, 0.088 \mathrm{mmol})$ was added. The solution was stirred at $\mathrm{rt}$ for $5 \mathrm{~min}$ before being capped and taken out of the drybox. The vial was then placed in an oil bath, heated to $100{ }^{\circ} \mathrm{C}$ for $3 \mathrm{~h}$, cooled to rt, filtered, and washed with $\mathrm{H}_{2} \mathrm{O}(25 \mathrm{~mL})$ and $\mathrm{MeOH}(25 \mathrm{~mL})$. The remaining polymer was suspended in conc. aqueous hydrochloric acid $(10 \mathrm{~mL})$ for $2 \mathrm{~h}$, filtered, washed with $\mathrm{H}_{2} \mathrm{O}(25 \mathrm{~mL})$ and $\mathrm{MeOH}(25 \mathrm{~mL})$, dried over dynamic vacuum, and activated at $150{ }^{\circ} \mathrm{C}$ under a flow of nitrogen for $15 \mathrm{~h}$ to give $\mathbf{A}_{2} \mathbf{B}_{1}(64 \mathrm{mg}, 98 \%)$ as a black amorphous powder. Elemental analysis for $\mathbf{A}_{2} \mathbf{B}_{1}$ : Calcd: $\mathrm{C}$, 86.87; H, 4.40. Found: C, 77.36; H, 5.14. The low $\mathrm{C}$ and high $\mathrm{H}$ experimental values can be attributed to the residual water content in our POPs even though the elemental analysis was carried out after the sample has been activated at $100{ }^{\circ} \mathrm{C}$.

$P O P A_{10} B_{1}$. In a glovebox, an 8 dram screw cap vial was charged with 2,3-(ethoxymethylenedioxy)-1,4-diethynylbenzene (A, $90 \mathrm{mg}$, $0.42 \mathrm{mmol}$ ) and tetrakis(4-ethynylphenyl)methane (B, $19 \mathrm{mg}, 0.04$ $\mathrm{mmol})$. This mixture was dissolved in dry, deoxygenated 1,4-dioxane $(5 \mathrm{~mL})$, and $\mathrm{Co}_{2}(\mathrm{CO})_{8}(60 \mathrm{mg}, 0.17 \mathrm{mmol})$ was added. The solution was stirred at rt for $5 \mathrm{~min}$ before being capped and taken out of the

Received: December 2, 2011

Revised: January 28, 2012

Published: January 31, 2012 
Scheme 1. Synthesis of Catechol-Containing POPs $A_{x} B_{y}$ Using a Cobalt-Catalyzed Acetylene Trimerization (CCAT) Strategy and Their Subsequent Metalation ${ }^{a}$

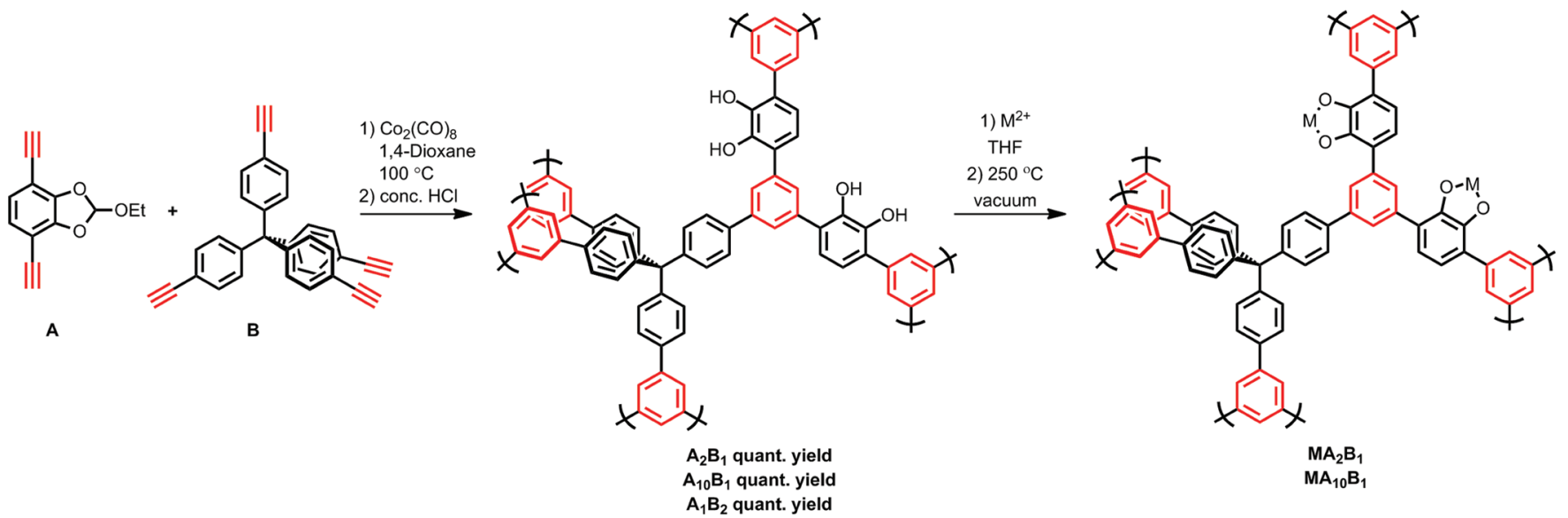

${ }^{a_{1}}$ The structures shown above are idealized representations of a completely formed network. In particular, 1,3,4-substitution patterns (as opposed to $1,3,5)$ may well be present. See the Supporting Information for additional discussion.

Table 1. Pore and Surface Properties of Catechol-Containing POPs $A_{x} B_{y}$ and $M A_{x} B_{y}$

\begin{tabular}{|c|c|c|c|c|c|c|c|c|}
\hline entry & POPs & $\begin{array}{l}\text { theoretical metal } \\
\text { loading (wt \%) }\end{array}$ & $\begin{array}{c}\text { actual metal } \\
\text { loading (wt \%) }\end{array}$ & $\begin{array}{l}\text { BET surface } \\
\text { area }\left(\mathrm{m}^{2} / \mathrm{g}\right)\end{array}$ & $\begin{array}{l}\text { total pore } \\
\text { volume } \\
\left(\mathrm{cm}^{3} / \mathrm{g}\right)\end{array}$ & $\begin{array}{l}\text { dominant DFT-calcd } \\
\text { Pore diameter (å) }\end{array}$ & $\begin{array}{c}\text { gravimetric } \mathrm{H}_{2} \\
\text { uptake }(\mathrm{wt} \%) \text { at } \\
77 \mathrm{~K}\end{array}$ & $\mathrm{Q}_{\mathrm{st}}(\mathrm{kJ} / \mathrm{mol})$ at $0-1$ \\
\hline 1 & $A_{2} B_{1}$ & & & 1050 & 0.41 & $12 \pm 2$ & 1.2 & $8.1-6.7$ \\
\hline 2 & $\mathrm{MgA}_{2} \mathrm{~B}_{1}$ & 6.3 & 6.1 & 610 & 0.17 & $9 \pm 2$ & 1.2 & $8.2-6.1$ \\
\hline 3 & $\mathrm{MnA}_{2} \mathbf{B}_{1}$ & 12.8 & 10.9 & 600 & 0.16 & $9 \pm 2$ & 1.1 & $9.1-7.4$ \\
\hline 4 & $A_{10} B_{1}$ & & & 617 & 0.25 & $12 \pm 2$ & 1.2 & $8.1-6.3$ \\
\hline 5 & $\operatorname{MgA}_{10} B_{1}$ & 10.9 & 10.6 & 205 & 0.08 & $11 \pm 2$ & 0.8 & $8.4-4.9$ \\
\hline 6 & $\operatorname{Mn} A_{10} B_{1}$ & 23.8 & 21.8 & 200 & 0.08 & $11 \pm 2$ & 0.7 & $9.6-9.5$ \\
\hline 7 & $\mathrm{CuA}_{10} \mathrm{~B}_{1}$ & 24.3 & 21.3 & 195 & 0.08 & $12 \pm 2$ & 1.0 & $8.5-7.4$ \\
\hline 8 & $A_{1} B_{2}$ & & & 560 & 0.22 & $12 \pm 2$ & & \\
\hline
\end{tabular}

drybox. The vial was then placed in an oil bath, heated to $100{ }^{\circ} \mathrm{C}$ for 3 h, cooled to rt, filtered, and washed with $\mathrm{H}_{2} \mathrm{O}(25 \mathrm{~mL})$ and $\mathrm{MeOH}$ $(25 \mathrm{~mL})$. The remaining polymer was suspended in concentrated aqueous hydrochloric acid $(10 \mathrm{~mL})$ for $2 \mathrm{~h}$, filtered, washed with $\mathrm{H}_{2} \mathrm{O}$ $(25 \mathrm{~mL})$ and $\mathrm{MeOH}(25 \mathrm{~mL})$, dried over dynamic vacuum, and activated at $150{ }^{\circ} \mathrm{C}$ under a flow of nitrogen for $15 \mathrm{~h}$ to give $\mathbf{A}_{10} \mathbf{B}_{1}$ (82 $\mathrm{mg}, 98 \%$ ) as a black amorphous powder. Elemental analysis. Calcd for $\mathbf{A}_{10} \mathbf{B}_{1}$ : C, 79.95; H, 4.04. Found: C, 70.61; H, 4.91.

$P O P A_{1} B_{2}$. In a glovebox, an 8 dram screw cap vial was charged with 2,3-(ethoxymethylenedioxy)-1,4-diethynylbenzene (A, $20 \mathrm{mg}, 0.09$ $\mathrm{mmol}$ ) and tetrakis(4-ethynylphenyl)methane (B, $76 \mathrm{mg}, 018 \mathrm{mmol})$. This mixture was dissolved in dry, deoxygenated 1,4-dioxane $(5 \mathrm{~mL})$, and $\mathrm{Co}_{2}(\mathrm{CO})_{8}(60 \mathrm{mg}, 0.17 \mathrm{mmol})$ was added. The solution was stirred at $\mathrm{rt}$ for $5 \mathrm{~min}$ before being capped and taken out of the drybox. The vial was then placed in an oil bath, heated to $100{ }^{\circ} \mathrm{C}$ for $3 \mathrm{~h}$, cooled to rt, filtered, and washed with $\mathrm{H}_{2} \mathrm{O}(25 \mathrm{~mL})$ and $\mathrm{MeOH}(25$ $\mathrm{mL})$. The remaining polymer was suspended in concentrated aqueous hydrochloric acid $(10 \mathrm{~mL})$ for $2 \mathrm{~h}$, filtered, washed with $\mathrm{H}_{2} \mathrm{O}(25 \mathrm{~mL})$, and $\mathrm{MeOH}(25 \mathrm{~mL})$, dried over dynamic vacuum, and activated at 150 ${ }^{\circ} \mathrm{C}$ under a flow of nitrogen for $15 \mathrm{~h}$ to give $\mathbf{A}_{1} \mathbf{B}_{2}$ (86 mg, 95\%) as a black amorphous powder. Elemental analysis. Calcd for $\mathbf{A}_{10} \mathbf{B}_{1}$ : C, 92.09; H, 4.68. Found: C, 84.42; H, 5.22.

2.2. Metalation of Polymers. The following protocols are representative metalation procedures for the synthesis of POPs $\mathrm{CuA}_{10} \mathrm{~B}_{1}, \mathrm{MnA}_{10} \mathrm{~B}_{1}$, and $\mathrm{MgA}_{10} \mathrm{~B}_{1}$.

$C u A_{10} B_{1} \cdot \mathbf{A}_{10} \mathbf{B}_{1}(80 \mathrm{mg})$ and $\mathrm{Cu}(\mathrm{OAc})_{2} \cdot \mathrm{H}_{2} \mathrm{O}(120 \mathrm{mg}, 0.60 \mathrm{mmol})$ were heated to $100{ }^{\circ} \mathrm{C}$ under vacuum for $2 \mathrm{~h}$, cooled to $\mathrm{rt}$, and suspended in dry, degassed THF $(10 \mathrm{~mL})$. This mixture was stirred at $50{ }^{\circ} \mathrm{C}$ for $18 \mathrm{~h}$, filtered directly into a Soxhlet extraction apparatus, and extracted with dry THF for $16 \mathrm{~h}$ under a $\mathrm{N}_{2}$ atmosphere. The remaining black material was filtered and activated at $250{ }^{\circ} \mathrm{C}$ under vacuum overnight.
$\mathrm{MnA}_{10} \boldsymbol{B}_{1} . \quad \mathbf{A}_{10} \mathbf{B}_{1}(47 \mathrm{mg})$ and $\mathrm{Mn}(\mathrm{OAc})_{2} \cdot 4 \mathrm{H}_{2} \mathrm{O}(110 \mathrm{mg}, 0.59$ $\mathrm{mmol}$ ) were heated to $100^{\circ} \mathrm{C}$ under vacuum $2 \mathrm{~h}$, cooled to rt, and suspended in dry, degassed THF $(10 \mathrm{~mL})$. This mixture was stirred at $50{ }^{\circ} \mathrm{C}$ for $18 \mathrm{~h}$, filtered directly into a Soxhlet extraction apparatus, and extracted with dry THF for $16 \mathrm{~h}$ under a $\mathrm{N}_{2}$ atmosphere. The remaining black material was filtered and activated at $250{ }^{\circ} \mathrm{C}$ under vacuum overnight.

$M g A_{10} B_{1} . A_{10} B_{1}(60 \mathrm{mg})$ was heated at $175{ }^{\circ} \mathrm{C}$ under vacuum for 2 $\mathrm{h}$, cooled to rt, and suspended in dry, degassed THF $(10 \mathrm{~mL})$. In a glovebox, $\mathrm{Me}_{2} \mathrm{Mg}$ ( $34 \mathrm{mg}, 0.63 \mathrm{mmol}$ ) was added as a solid to this suspension, and the resulting mixture was stirred at $\mathrm{rt}$ for $18 \mathrm{~h}$. The resulting suspended solid was filtered directly into a Soxhlet extraction apparatus and extracted with dry THF for $16 \mathrm{~h}$ under a $\mathrm{N}_{2}$ atmosphere. The remaining black material was filtered and activated at $250{ }^{\circ} \mathrm{C}$ under vacuum overnight.

\section{RESULTS AND DISCUSSION}

In designing the catechol-containing POP, we selected the cobalt-catalyzed acetylene trimerization (CCAT) reaction for its good polymerization kinetics and the robustness of the network formed. ${ }^{24} \mathrm{Liu}, \mathrm{Yu}$, and co-workers have shown this trimerization protocol to be an attractive means for producing POPs with surface areas up to $\sim 1000 \mathrm{~m}^{2} / \mathrm{g}$ from $1,4-$ diethynylbenzene alone. ${ }^{25,26}$ Lin and co-authors have also prepared acetylene-trimerization-derived POPs exhibiting photocatalytic $^{16}$ and catalytic ${ }^{27}$ properties. We hypothesized that by copolymerizing a catechol-containing monomer, 1,4diethynyl-2,3-dihydroxybenzene with the $T_{\mathrm{d}}$-directing tetrakis(4-ethynyl)methane monomer B (Scheme 1), the resulting networks would become inherently three-dimensional and 
therefore display even greater porosity. Our initial attempts to copolymerize these two monomers resulted in no product, presumably due to the well-known chelating ability of the catechol moiety, ${ }^{1}$ whose presence would tie up the propagating Co species. However, once 1,4-diethynyl-2,3-dihydroxybenzene was protected with an acid-labile orthoester group, ${ }^{28}$ the $2: 1$ copolymerization of the protected monomer $\mathbf{A}$ with $\mathbf{B}$ afforded POP $\mathbf{A}_{2} \mathbf{B}_{1}$ with a $1050 \mathrm{~m}^{2} / \mathrm{g}$ BET surface area (Scheme 1, Table 1). Interestingly, varying the $\mathbf{A}: \mathbf{B}$ stoichiometric ratio in either direction results in much less porous materials $\left(670 \mathrm{~m}^{2} / \mathrm{g}\right.$ for POP $\mathbf{A}_{10} \mathbf{B}_{1}$ and $560 \mathrm{~m}^{2} / \mathrm{g}$ for POP $\left.\mathbf{A}_{1} \mathbf{B}_{2}\right)$. Indeed, by varying the ratio of tetraacetylene $\mathbf{B}$ to diacetyelene $\mathbf{A}$, both the surface area and the catechol loading of POPs $\mathbf{A}_{x} \mathbf{B}_{\boldsymbol{y}}$ were readily tuned (Table 1). We note that while a porous material has been obtained from the homotrimerization of 1,4-diethynylbenzene, $^{26}$ the homotrimerization of $\mathbf{A}$ in our hands afforded a solid with no significant porosity toward either $\mathrm{N}_{2}(77 \mathrm{~K})$ or $\mathrm{CO}_{2}$ (273K) (Figure S15 in the Supporting Information).

After polymerization, the catechol-containing POPs $\mathbf{A}_{x} \mathbf{B}_{y}$ were thoroughly washed with concentrated hydrochloric acid, which cleaved the labile orthoester groups, as indicated by solid-state (SS) NMR spectroscopy (Figure 1), as well as any

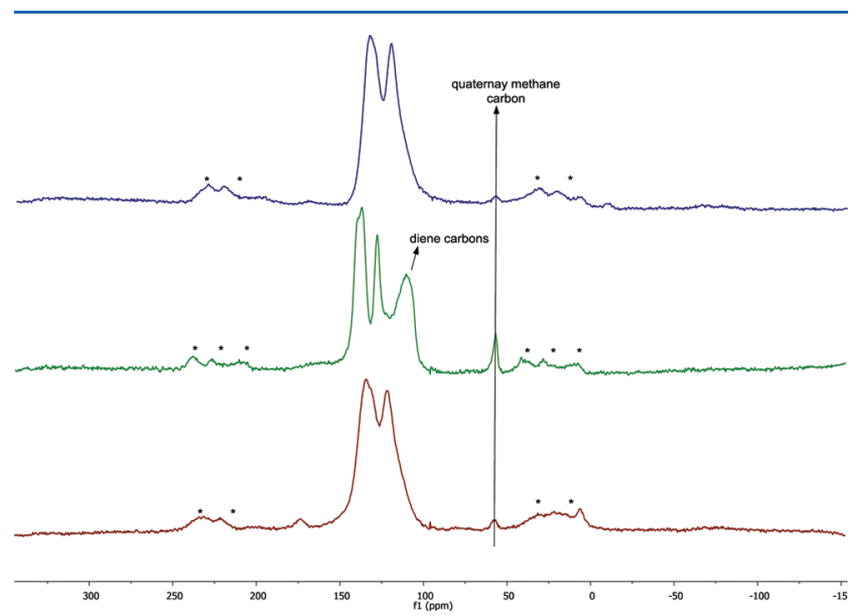

Figure 1. Solid-state ${ }^{13} \mathrm{C}$ NMR spectra for $\mathbf{A}_{2} \mathbf{B}_{1}$ (blue, top), $\mathbf{A}_{10} \mathbf{B}_{1}$ (green, middle), and 1-hexyne capped $\mathbf{A}_{10} \mathbf{B}_{1}$ (red, bottom), where * represents spinning side bands.

residual organocobalt termini, as confirmed by inductively coupled plasma optical emission spectroscopy (ICP-OES). To our pleasant surprise, the integrity of the deprotected catechol moiety, which has been known to undergo oxidation to the corresponding orthoquinone, ${ }^{29}$ was not significantly compromised during the acid wash, as established both by IR spectroscopy (Figure S2 in the Supporting Information) and by a Prussian blue-dye test (see Figure S5 in the Supporting Information). ${ }^{30}$

Consistent with the aforementioned discussion of catechol group stability, the solid-state (SS) ${ }^{13} \mathrm{C}$ NMR spectra of POPs $\mathbf{A}_{x} \mathbf{B}_{y}$ reveal no quinoidal peak. Interestingly, the SS ${ }^{13} \mathrm{C} N \mathrm{NMR}$ spectrum of POP $\mathbf{A}_{10} \mathbf{B}_{\mathbf{1}}$ (Figure 1, middle spectrum) reveals a significant number of terminal olefin/diene groups indicating incomplete aromatization (Scheme S1 in the Supporting Information). If the reaction mixture is treated with 1 -hexyne prior to acid work up, these exposed moieties can be capped, resulting in near-complete elimination of the SS ${ }^{13} \mathrm{C}$ NMR resonances due to olefin/diene groups (Figure 1, bottom spectrum, and Scheme S1 in the Supporting Information). As the $\mathbf{A}: \mathbf{B}$ ratio is decreased, materials that are free of olefin/diene groups can be obtained directly, as evidenced by the $S S{ }^{13} \mathrm{C}$ NMR spectrum of POP $\mathbf{A}_{2} \mathbf{B}_{1}$ (Figure 1, top spectrum). POPs $\mathbf{A}_{10} \mathbf{B}_{1}$ and $\mathbf{A}_{2} \mathbf{B}_{1}$ exhibit similar thermal stabilities (up to $\sim 250$ ${ }^{\circ} \mathrm{C}$ ) as shown by thermal gravimetric analysis (TGA, Figures S37-S38 in the Supporting Information).

The catechol-decorated CCAT-POPs can readily be metalated with a wide range of metal precursors (i.e., salts and complexes). Treatment of either $\mathbf{A}_{2} \mathbf{B}_{1}$ or $\mathbf{A}_{10} \mathbf{B}_{1}$ with excess metal precursors $\left(\mathrm{MgMe}_{2}, \mathrm{Cu}(\mathrm{OAc})_{2}\right.$, or $\left.\mathrm{Mn}(\mathrm{OAc})_{2}\right)$ afforded the corresponding metalated POP derivatives with close to quantitative loading of the catechol groups, consistent with the aforementioned absence of orthoquinone functionalities and suggesting a 1:1 catechol:metal stoichiometry (Table 1). The thermal stabilities of the metalated POPs are similar to those for the nonmetalated versions (Figures S37-S40 in the Supporting Information), but with expectedly lower BET surface areas (Table 1, Figure 2) and pore diameters (Table 1

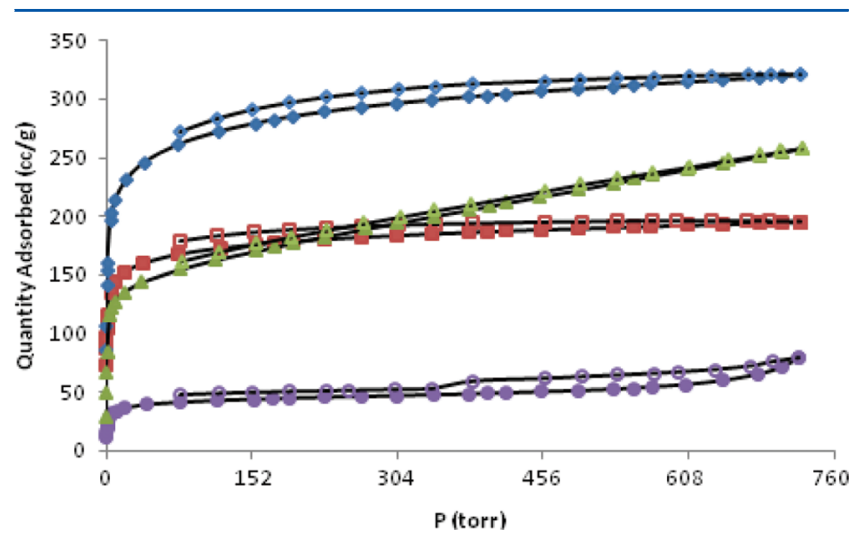

Figure 2. Nitrogen isotherms measured at $77 \mathrm{~K}$ for polymers $\mathbf{A}_{2} \mathbf{B}_{1}$ (blue diamond), $\mathbf{A}_{10} \mathbf{B}_{1}$ (red square), $\mathbf{M n A}_{2} \mathbf{B}_{1}$ (green triangle), and $\mathbf{M n A}_{10} \mathbf{B}_{1}$ (purple circle). Closed symbols, adsorption; open symbols, desorption.

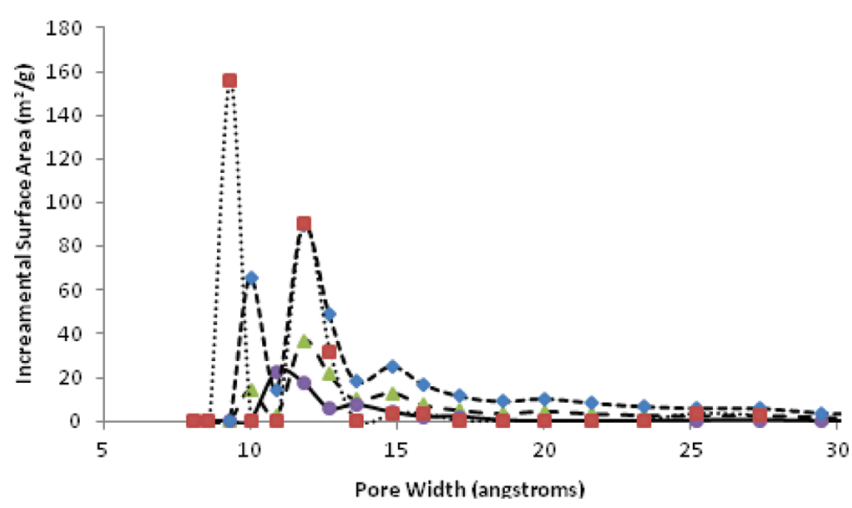

Figure 3. Pore size distributions based on DFT calculations (slit-pore model) for $\mathbf{A}_{2} \mathbf{B}_{1}$ (blue diamond), $\mathbf{M n A}_{2} \mathbf{B}_{1}$ (red square), $\mathbf{A}_{10} \mathbf{B}_{1}$ (green triangle), and $\mathbf{M n A}_{10} \mathbf{B}_{1}$ (purple circle).

and Figure 3; see also Figures S6-S15 in the Supporting Information). As expected, the three metalated $\mathbf{M A}_{10} \mathbf{B}_{1}$ materials show similar specific surface areas, pore volumes, and pore diameters (Table 1). Treatment of $\mathbf{M n} \mathbf{A}_{10} \mathbf{B}_{1}$ with concentrated aqueous $\mathrm{HCl}$ at $50{ }^{\circ} \mathrm{C}$ afforded a completely demetalated sample, as confirmed by ICP-OES (see Section S3 
in the Supporting Information), illustrating the reversibility of the metalation step; however, the BET surface area $\left(610 \mathrm{~m}^{2} / \mathrm{g}\right)$ does not completely recover (Figure $\mathrm{S} 14$ in the Supporting Information).

The IR spectrum for $\mathbf{M n} \mathbf{A}_{\mathbf{1 0}} \mathbf{B}_{\mathbf{1}}$ (Figure S2 in the Supporting Information) shows a decrease in the intensity of the $\mathrm{OH}$ vibrations in the metalated POP compared to that in the spectrum of either $\mathbf{A}_{10} \mathbf{B}_{1}$ or a mixture of $\mathbf{A}_{10} \mathbf{B}_{1}$ and $\left.\mathrm{Mn}(\mathrm{OAc})_{2} \cdot 4 \mathrm{H}_{2} \mathrm{O}\right)$. In addition, there is an absence of the carbonyl stretch attributed to ligated acetate ligand in the parent metal precursor. Together with the known instability of orthoquinones, ${ }^{31}$ these results suggest that the catechol units maintain their hydroxy functionalities, the majority of which are available for metal complexation.

Treatment of $\mathbf{M n} \mathbf{A}_{10} \mathbf{B}_{1}$ with a substoichiometric ( 0.75 equiv $\mathrm{I} / \mathrm{Mn}$ ) amount of $\mathrm{I}_{2}$ in chloroform afforded a near-colorless solution, presumably due to the oxidation of the catecholate $\mathrm{Mn}^{\mathrm{II}}$ species to a $\mathrm{Mn}^{\mathrm{III}}$ iodo species. ${ }^{32}$ Together with the results mentioned above, this observation suggests that the $\mathrm{Mn}(\mathrm{OAc})_{2}$ precursor metallates $\mathbf{A}_{10} \mathbf{B}_{1}$ in a nonredox manner that maintains the $\mathrm{Mn}^{\mathrm{II}}$ oxidation state and the catecholate functionality. As a control, the nonmetalated parent POP $\mathbf{A}_{10} \mathbf{B}_{1}$ does not decolorize an iodine solution.

Finally, we briefly examined the effects of POP metalation upon hydrogen sorption at $77 \mathrm{~K}$ and $1 \mathrm{~atm}$. POPs $\mathbf{A}_{2} \mathbf{B}_{1}$ and $\mathbf{A}_{10} \mathbf{B}_{1}$ take up nearly identical amounts of hydrogen even though their BET surface areas are quite different (Table 1, cf. entries 1 and 4). Perhaps more surprising are the very similar values for hydrogen uptake (on a gravimetric basis) for POP $\mathbf{A}_{2} \mathbf{B}_{1}$ and its two metalated congeners, despite much lower BET surface areas and total pore volumes (Table 1, cf. entries 1-3; see also Figures S6-S15 in the Supporting Information). One possibility is that reductions in surface area and pore volume are compensated at low loadings by increased heats of adsorption (see below). ${ }^{33}$ Another possibility is that reductions in the surface area accessible to $\mathrm{H}_{2}$ may be less than reductions in the surface area accessible to $\mathrm{N}_{2}$, a larger molecule. Only in the case of POP $\mathbf{A}_{10} \mathbf{B}_{1}$, where metalation can be carried out at much higher loadings, leading to materials with drastically lower total pore volumes and surface areas, do metalated materials begin to show significantly less hydrogen uptake $(0.70-1.02 \mathrm{wt} \%)$ than shown by the parent POP (1.20 wt \%) (Table 1, cf. entries 4-7; Figure 4). While it is tempting to ascribe the changes to chemical effects, a significant portion of

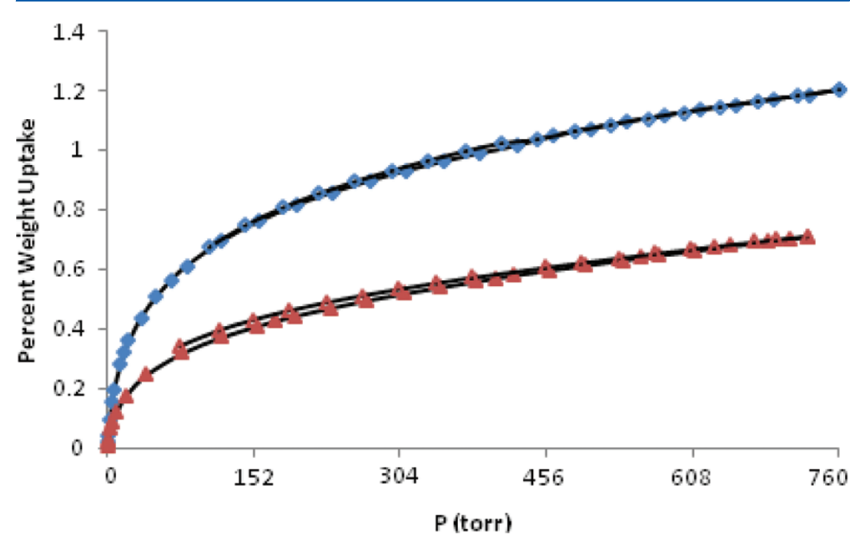

Figure 4. Hydrogen adsorption-desorption isotherms at $77 \mathrm{~K}$ and 1 bar for $\mathbf{A}_{10} \mathbf{B}_{1}$ (blue diamond) and $\mathbf{M n A}_{10} \mathbf{B}_{1}$ (red triangle). Closed symbols, adsorption; open symbols, desorption. the difference can be rationalized by recognizing that metalation increases the mass of the POP.

As would be expected for materials possessing coordinatively unsaturated Lewis acidic metal sites, ${ }^{34,35}$ the isosteric heats of hydrogen adsorption $\left(Q_{t}\right)$ for the metalated POPs are higher than those for the parent materials (Table 1). Most notable is the $\sim 1.5 \mathrm{~kJ} / \mathrm{mol}$ enhancement in $\mathrm{Q}_{\mathrm{st}}$ for $\mathbf{M n A}_{\mathbf{1 0}} \mathbf{B}_{\mathbf{1}}(9.6 \mathrm{~kJ} / \mathrm{mol})$ compared to that for its parent POP. The $Q_{t}$ values for this material also remain remarkably constant over the $0-1$ atm range of $\mathrm{H}_{2}$ pressure (Figure 5). We attribute this behavior to a

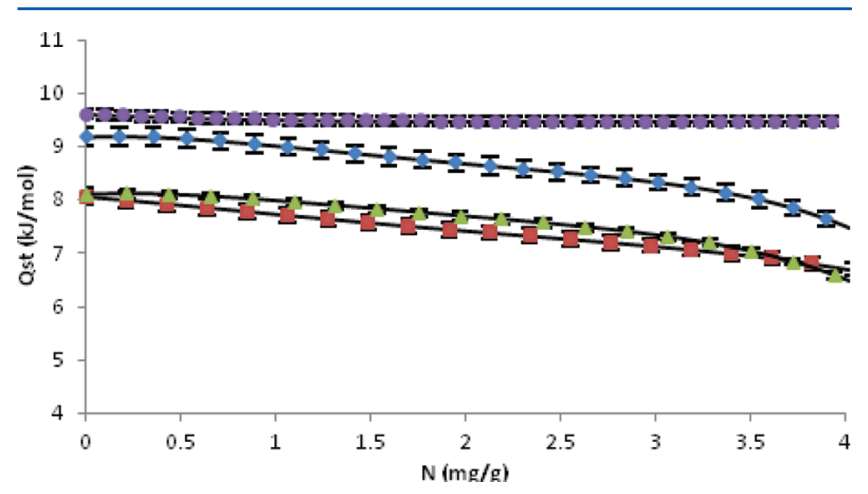

Figure 5. Heats-of-hydrogen adsorption $\left(Q_{s t}\right)$ plots for $\mathbf{M n} \mathbf{A}_{\mathbf{1 0}} \mathbf{B}_{\mathbf{1}}$ (purple circle), $\mathbf{M n} \mathbf{A}_{2} \mathbf{B}_{1}$ (blue diamond), $\mathbf{A}_{10} \mathbf{B}_{1}$ (red square), and $\mathbf{A}_{2} \mathbf{B}_{1}$ (green triangle).

combination of effects as the metal loading increased: significant charge/quadrupole or charge/induced-dipole interactions between manganese ions and hydrogen molecules ${ }^{34}$ and generally stronger interactions between the POP and hydrogen molecules as pores narrow.

\section{SUMMARY AND CONCLUSIONS}

In summary, we have synthesized a class of catechol-decorated porous organic polymers (POPs) that can be metalated with a wide range of metal complexes to afford porous cavities that feature coordinatively unsaturated, monocatecholated metal centers. The readily available starting monomers and the robustness of the CCAT methodology allow for facile tuning of surface areas and the extent of metal loading. Notably, loading $\mathrm{Mn}^{\mathrm{II}}$ at a high level results in a POP that displays a comparatively high isosteric heat of $\mathrm{H}_{2}$ adsorption that remains constant over the $0-1 \mathrm{~atm}$ pressure range- a feature that if achievable over a broader pressure range with materials that interact more strongly with $\mathrm{H}_{2}$ would be highly desirable in the context of reversible hydrogen storage.

\section{ASSOCIATED CONTENT}

\section{S Supporting Information}

Complete procedures for the synthesis of additional POPs and characterization data (FTIR, TGA, ${ }^{13} \mathrm{C}$ CPMAS NMR) for all POPs; nitrogen, carbon dioxide, and hydrogen adsorption isotherms; heat of adsorption calculations; and pore size distribution graphs. This material is available free of charge via the Internet at http://pubs.acs.org.

\section{AUTHOR INFORMATION}

\section{Corresponding Author}

*E-mail: o-farha@northwestern.edu (O.K.F.), j-hupp@ northwestern.edu (J.T.H.), and stn@northwestern.edu (S.T.N.). 


\section{Notes}

The authors declare no competing financial interest.

\section{ACKNOWLEDGMENTS}

Instruments in the Northwestern University Integrated Molecular Structure Education and Research Center (IMSERC) were purchased with grants from NSF-NSEC, NSFMRSEC, Keck Foundation, the state of Illinois, and Northwestern University. Financial support for this work is provided by DTRA (Agreement HDTRA1-10-1-0023) and the AFOSR (Agreement FA-9550-07-1-0534). Support for the hydrogenuptake measurements is provided by the US DOE-EERE (Grant No. DE-FG36-08GO18137/A001).

\section{REFERENCES}

(1) Pierpont, C. G.; Lange, C. W. Prog. Inorg. Chem. 2007, 41, 331442.

(2) Schwab, M. G.; Fassbender, B.; Spiess, H. W.; Thomas, A.; Feng, X.; Müllen, K. J. Am. Chem. Soc. 2009, 131, 7216-7217.

(3) Tozawa, T.; Jones, J. T. A.; Swamy, S. I.; Jiang, S.; Adams, D. J.; Shakespeare, S.; Clowes, R.; Bradshaw, D.; Hasell, T.; Chong, S. Y.; Tang, C.; Thompson, S.; Parker, J.; Trewin, A.; Bacsa, J.; Slawin, A. M. Z.; Steiner, A.; Cooper, A. I. Nat. Mater. 2009, 8, 973-978.

(4) McKeown, N. B.; Budd, P. M. Macromolecules 2010, 43, 51635176

(5) Germain, J.; Svec, F.; Fréchet, J. M. J. Chem. Mater. 2008, 20, 7069-7076.

(6) El-Kaderi, H. M.; Hunt, J., R.; Mendoza-Cortés, J. L.; Côté, A. P.; Taylor, R. E.; O’Keeffe, M.; Yaghi, O. M. Science 2007, 316, 268-272.

(7) Weber, J.; Thomas, A. J. Am. Chem. Soc. 2008, 130, 6334-6335.

(8) Ben, T.; Ren, H.; Ma, S.; Cao, D.; Lan, J.; Jing, X.; Wang, W.; Xu, J.; Deng, F.; Simmons, J.; Qiu, S.; Zhu, G. Angew. Chem., Int. Ed. 2009, 48, 9457-9460

(9) Cooper, A. I. Adv. Mater. 2009, 21, 1291-1295.

(10) Yuan, D.; Lu, W.; Zhao, D.; Zhou, H.-C. Adv. Mater. 2011, 23, $3723-3725$.

(11) Thomas, A.; Kuhn, P.; Weber, J.; Titirici, M.-M.; Antonietti, M. Macromol. Rapid Commun. 2009, 30, 221-236.

(12) Rabbani, M. G.; El-Kaderi, H. M. Chem. Mater. 2011, 23, 16501653.

(13) Kaur, P.; Hupp, J. T.; Nguyen, S. T. ACS Catal. 2011, 1, 819835.

(14) Mackintosh, H. J.; Budd, P. M.; McKeown, N. B. J. Mater. Chem. 2008, 18, 573-578.

(15) Shultz, A. M.; Farha, O. K.; Hupp, J. T.; Nguyen, S. T. Chem. Sci. 2011, 2, 686-689.

(16) Xie, Z.; Wang, C.; de Krafft, K. E.; Lin, W. J. Am. Chem. Soc. 2011, 133, 2056-2059.

(17) Jiang, J.-X.; Cooper, A. I. Top. Curr. Chem. 2010, 293, 1-33.

(18) Jiang, J.-X.; Wang, C.; Laybourn, A.; Hasell, T.; Clowes, R; Khimyak, Y. Z.; Xiao, J.; Higgins, S. J.; Adams, D. J.; Cooper, A. I. Angew. Chem., Int. Ed. 2011, 50, 1072-1075.

(19) Farha, O. K.; Spokoyny, A. M.; Hauser, B. G.; Bae, Y.-S.; Brown, S. E.; Snurr, R. Q.; Mirkin, C. A.; Hupp, J. T. Chem. Mater. 2009, 21, 3033-3035.

(20) McKeown, N. B.; Budd, P. M. Chem. Soc. Rev. 2006, 35, 675683.

(21) Lu, W.; Yuan, D.; Sculley, J.; Zhao, D.; Krishna, R.; Zhou, H.-C. J. Am. Chem. Soc. 2011, 133, 18126-18129.

(22) Farha, O. K.; Bae, Y.-S.; Hauser, B. G.; Spokoyny, A. M.; Snurr, R. Q.; Mirkin, C. A.; Hupp, J. T. Chem. Commun. 2010, 46, 10561058.

(23) Pandey, P.; Farha, O. K.; Spokoyny, A. M.; Mirkin, C. A.; Kanatzidis, M. G.; Hupp, J. T.; Nguyen, S. T. J. Mater. Chem. 2011, 21, $1700-1703$.

(24) Saito, S.; Yamamoto, Y. Chem. Rev. 2000, 100, 2901-2916.
(25) Yuan, S.; Kirklin, S.; Dorney, B.; Liu, D.-J.; Yu, L. Macromolecules 2009, 42, 1554-1559.

(26) Yuan, S.; Dorney, B.; White, D.; Kirklin, S.; Zapot, P.; Yu, L.; Liu, D.-J. Chem. Commun. 2010, 4547-4549.

(27) Ma, L.; Wanderley, M. M.; Lin, W. ACS Catal. 2011, 1, 691697.

(28) Merz, A.; Rauschel, M. Synthesis 1993, 797-802.

(29) Branch, G. E. K.; Joslyn, M. A. J. Am. Chem. Soc. 1935, 57, $2388-2394$

(30) Guo, L.; Zhang, Y.; Li, Q. Anal. Sci. 2009, 25, 1451-1455.

(31) Ball, E. G.; Clark, W. M. Proc. Natl. Acad. Sci. U.S.A. 1931, 17, 347-351.

(32) Gallo, E.; Solari, E.; Re, N.; Floriani, C.; Chiesi-Villa, A.; Rizzoli, C. J. Am. Chem. Soc. 1997, 119, 5144-5154.

(33) Frost, H.; Düren, T.; Snurr, R. Q. J. Phys. Chem. B 2006, 110, 9565-9570.

(34) Getman, R. B.; Miller, J. H.; Wang, K.; Snurr, R. Q. J. Phys. Chem. C 2010, 115, 2066-2075.

(35) Murray, L. J.; Dincă, M.; Long, J. R. Chem. Soc. Rev. 2009, 38, $1294-1314$. 